\title{
The seminal work of Werner Risau in the study of the development of the vascular system
}

\author{
DOMENICO RIBATTI* \\ Department of Human Anatomy and Histology, University of Bari Medical School, Bari, Italy
}

\begin{abstract}
Werner Risau's work had a decisive impact on defining the overall nature of neovascularization processes during development and had the capability to integrate different directions in the field of endothelial cell biology research. In particular, he had a special interest in understanding the development, differentiation and maintenance of the blood-brain barrier. Risau very successfully propagated the concept that the same factors, such as basic fibroblast growth factor (bFGF) and vascular endothelial growth factor (VEGF), which are essential for the formation of blood vessels during embryonic development, also influence pathological angiogenesis during tumor growth. This review is dedicated to a retrospective analysis of the most important contributions of Risau's work in the field of angiogenesis during embryonic development and in post-natal life, in both physiological and pathological conditions.
\end{abstract}

KEY WORDS: angiogenesis, blood-brain barrier, history of medicine, vascular endothelial growth factor

\section{Introduction}

Werner Risau was born on December 18, 1953. He studied Chemistry and Biochemistry at the University of Münster and Tübingen, before he went in 1984 to the laboratory of Judah Folkman at the Children's Hospital of the Harvard Medical School, Boston. In 1999, Folkman wrote that: "He had written to me that he wished to learn the arcane world of endothelial cells and the growth factors that regulate them. I answered that there was only one such factor, bFGF, and the existing supply was only a few micrograms, but that he was welcome to come nevertheless. $\mathrm{He}$ did.He quickly became an expert and then a pioneer on the role of this protein in neovascularization, and he also became intrigued with studying the development of the vascular system in the chick embryo (...) After he completed his fellowship and had left our lab, we watched with great pride his meteoric rise as a distinguished scientist known throughout the world. His seminal studies established the molecular mechanisms of VEGF and its receptors, pioneered the identification of cell lineages in the vascular system, and laid the ground work for a molecular distinction between vasculogenesis and angiogenesis."

Risau worked initially in Junior Group leader position at the Max Planck Institute for Experimental Biology in Tübingen and thereafter at the Max Planck Institute for Psichiatry, Department of Neurochemistry at Martinsried close to Munich (Figure 1). In 1993 he was appointed to the position of a Director at the Max
Planck Institute for Physiology and Clinical Research in Bad Nauheim, until his death at age of 44 on December 13, 1998.

Risau's work had a decisive impact on defining the overall nature of neovascularization process during embryonic development. He propagated the concept that the same factors, which are essential for the formation of blood vessels during embryonic development, also influence pathological angiogenesis during tumor growth.

\section{Changes in extracellular matrix during embryonic vasculogenesis and angiogenesis}

The extracellular matrix of the developing blood vessels modifies its composition in terms of expression of fibronectin, laminin, collagen type IV and distribution of specific glycosaminoglycans (Ausprunk, 1986).

Risau demonstrated that blood islands in the yolk sac produced high levels of fibronectin but not laminin, whereas all intraembryonic blood vessels are surrounded by a fibronectin-rich

\footnotetext{
Abbreviations used in this paper: aFGF, acidic basic fibroblast growth factor; bFGF, basic fibroblast growth factor; BBB, blood brain barrier; flk-1, fetal liver kinase-1; HIF, hypoxia inducible factor; PDGF, platelet derived growth factor; PNP, perinecrotic palisanding cells; SDF-1, stromal cell derived factor-1; VEGF, vascular endothelial growth factor; VEGFR, vascular endothelial growth factor receptor.
}

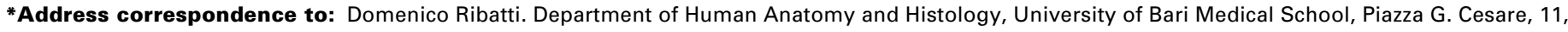
Policlinico, I-70124 Bari, Italy. Fax: +39-080-5478310. e-mail: ribatti@anatomia.uniba.it
} 
extracellular matrix early in the development, which is susequently remodeled into a basement membrane-like matrix (Risau and Lemmon, 1988). Capillary sprouts invading the neuroectoderm migrated in a fibronectin-rich matrix devoid of laminin. Ultrastructural immunolocalization demonstrated the presence of fibronectin exclusively on the abluminal site of endothelial cells. Around larger vessels (e.g. dorsal aorta) several layers of fibronectinexpressing cells can be observed early on, but are devoid of laminin.

Overall, Risau amd Lemmon proposed that laminin is an early marker for vascular maturation.

\section{Characterization of fetal liver kinase-1 (flk-1)}

Flk-1 is the first endothelial receptor tyrosine kinase known to be expressed on endothelial cell precursors and plays a central role in regulating embryonic vascular development and tumor angiogenesis. Mice deficient in flk-1 died in utero between days 8.5 and 9.5 postcoitum, as a result of an early defect in the development of hematopoietic and endothelial cells and a complete lack of vasculature (Shalaby et al., 1995).

Risau and co-workers (Kabrun et al., 1997) investigated the expression of pattern of vascular endothelial growth factor receptor-2 (VEGFR-2) in mouse embryonic and fetal hematopoietic tissues as well as on hematopoietic tissues derived from these tissues and demonstrated that flk-1 expression provides a marker for the earliest detectable hematopoietic precursors. RNA analysis indicated that flk-1 was expressed in the yolk sac at day 10 and 12 of gestation, in the liver throughout fetal life and embryoid bodies. Flk-1 was also detected in erythroid and macrophage colonies generated from precursors of yolk sac, fetal liver, adult marrow and embryo bodies origin.

Risau and co-workers (Rönicke et al., 1996) isolated genomic clones that encompass the promoter region of the murine flk-1 gene and performed a functional analysis of the flk-1 promoter in vivo. They demonstrated that flk-1 5'-flanking sequences confer endothelium-specific expression in transfected endothelial cells. In a paper published in 1999, after Risau death, Kappel et al. (1999) characterized regulatory sequences in transgenic mice. Despite their activity in cultured endothelial cells, 5'-flanking sequences alone could not target expression of a LacZ reporter gene to the endothelium of murine embryos. However, in combination with sequences form the first intron of the flk-1 gene, the flk1 promoter could specifically drive reporter gene expression in endothelial cells.

Risau and co-workers (Kappel et al., 2000) identified by mutational analysis binding sites for SCL/Tal-1, GATA, and Ets transcription factors as critical elements for the endothelium-specific flk-1 gene espression in transgenic mice, providing the first evidence that SCL/Tal-1, GATA, and Ets transcription factors act up-stream of flk-1 in a combinatorial fashion to determine embryonic blood vessel formation and are key regulators not only of hematopoiesis, but also of vascular development.

\section{Embryonic brain angiogenesis}

Risau focused his interest on the vascularization of the brain, where a primary plexus surrounds the neural tube. From this plexus capillary sprouts invade the neuroectoderm. The endothe- lial cells migrate deep into the neuroectoderm and form capillary branches into the subependymal layer. This process is regulated by the developing organ itself and seems to be dependent on the growth and differentiation of cells present in the brain.

Risau characterized endothelial cell growth and angiogenic factors from embryonic chick brain extracts, two of which were identified as acidic and basic fibroblast growth factor (aFGF and bFGF) (Risau, 1986; Risau et al., 1988). The mitogenic activity in chick brain was found to increase several hundred fold during embryonic chick brain development and reached a plateau at around day 14. The mRNA levels of the chick aFGF gene showed a similar pattern during brain development (Schnürch and Risau, 1991). However, growth factor activity and aFGF as well as bFGF gene transcription is not down-regulated concomitantly with cessation of endothelial cell growth in postnatal brain and these factors are most abundant in the adult brain when angiogenesis has ceased (Schnürch and Risau, 1991). This suggest that either the activity of these factors is inhibited in the later stages of development or that these factors are not involved in embryonic brain angiogenesis. Furthermore, both aFGF and bFGF do not possess a hydrophobic signal sequence needed for efficient secretion from their producer cells, and their mode of secretion is unknown.

\section{The role of vascular endothelial growth factor in brain angiogenesis}

Over the years, five VEGF related genes have been identified (VEGF-A, VEGF-B, VEGF-C, VEGF-D and VEGF-E). There are five characterized VEGF-A isoforms of $121,145,165,189$, and 206 amino acids in mammals, generated by alternative splicing of the mRNA from a single gene comprising eight exons. They

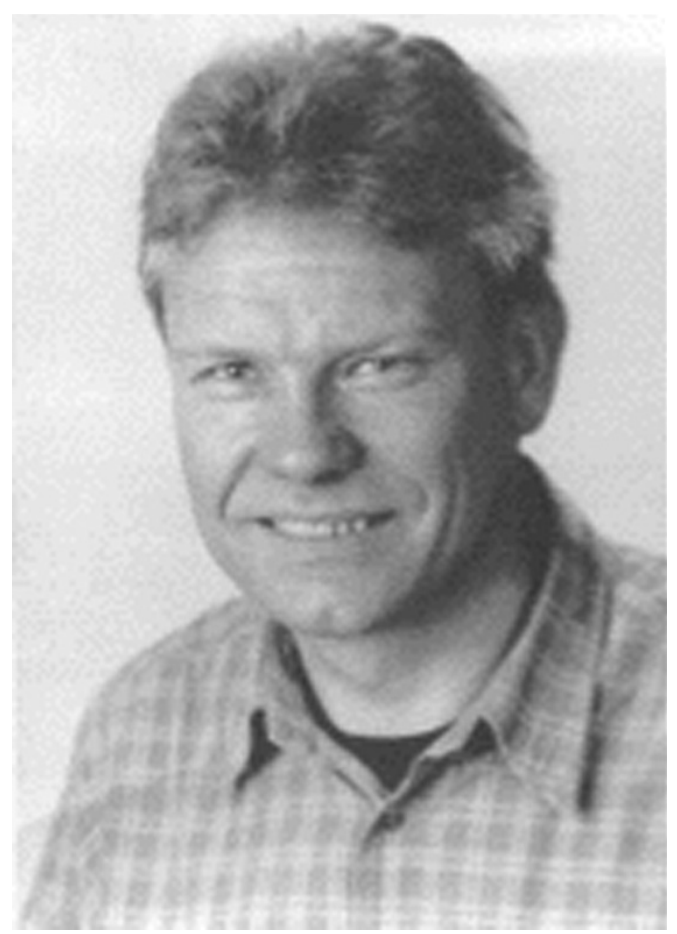

Fig. 1. A portrait of Werner Risau (reproduced from Angiogenesis, 3: 58,1999, Kluwer Academic Publishers) 
display differential interactions with related receptor tyrosine kinases VEGFR-1/Flt-1, VEGFR-2/Flk-1, VEGFR-3/Flt-4, and neuropilin-1 an -2 . As a result of the receptor activation and subsequent signal transduction, VEGF target cells may proliferate, migrate or alter gene expression, eg. of matrix metalloproteinases or cytokines (Ribatti, 2005; 2008).

Risau cloned the gene encoding mouse VEGF and found that the spatial and the temporal expression pattern of VEGF mRNA correlated with angiogenesis during embryonic development in the mouse brain (Breier et al., 1992). By in situ hybridization, Risau and co-workers showed that in day 17 mouse embryos VEGF mRNA was expressed in the ventricular layer of the developing neuroectoderm. A concentration gradient of the diffusible VEGF isforms declining from the ventricular layer towards the perineural vascular plexus may cause the radial ingrowth of capillaries from the vascular plexus towards the angiogenic stimulus provided by VEGF secreting ventricular epithelial cells (Breier et al., 1992). In contrast to the transient expression in ependymal cells, VEGF expression persisted in the choroid plexus epithelium of the brain on adult mice, when vascularization of these structures is complete.

Risau and co-workers isolated an high affinity VEGF-receptor from proliferating endothelial cells of postnatal day 4-10 mouse brain, when there was maximal endothelial cell proliferation (Millauer et al., 1993). This VEGF receptor belong to the family of receptor tyrosine kinases and had previously designated flk-1 (Matthews et al., 1991). In situhybridization in the embryonic day 14.5 mouse embryo revealed that flk- 1 was restricted to capillaries and blood vessels. At day 11.5 in the mouse embryo when the first vascular sprouts begin to radially invade the neuroectoderm form the perineural plexus, expression of flk-1 was high in the perineural vascular plexus and in invading vascular sprouts (Millauer et al., 1993). At embryonic day 14.5, when the neuroectoderm is already highly vascularized, numerous radial vessels as well as branching vessels of the intraneural plexus contained large amounts of flk-1 mRNA (Millauer et al., 1993). Finally, in the adult brain, when angiogenesis has ceased, flk-1 expression was very low and restricted to the choroid plexus endothelial cells.

Risau and co-workers demonstrated that flk-1 was highly expressed in early postnatal mouse brain but was down-regulated at postnatal day 15 and was hardly detectable at postnatal day 30 (Kremer et al., 1997). Moreover, they observed that hypoxia up-regulated flk-1 in postnatal day 30 mouse brain slices, suggesting the presence of a hypoxia-inducible factor in the murine neuroectoderm that up-regualated flk-1.

The specific role of VEGF as an embryonic angiogenesis factor was further supported by experiments in which VEGF was overexpressed in the limb of chick embryos, resulting in hypervascularization without alteration of limb morphogenesis (Flamme et al., 1995).

Risau described an additional endothelial cell-specific receptor tyrosine kinase, tie 2 (tek) in developing vasculature of the brain, which is down-regulated in adult organism (Schnürch and Risau, 1993).

\section{Characterization of the blood-brain barrier}

Although there has been considerably controversy since the observation by Ehrlich more than 100 years ago that the brain did not take up dyes from the vascular system, the concept of an endothelial blood brain barrier (BBB) was confirmed by the unequivocal demonstration that the passage of molecules from blood to brain and vice-versa was prevented by endothelial tight junctions. There are three major functions implicated in the term BBB: 1) protection of the brain from the blood mileu; 2) selective transport and, 3) metabolism or modification of blood- or brainborne substances.

The BBB phenotype develops under the influence of associated brain cells, especially astrocytic glia, and consists of complex tight junctions and a number of specific transport and enzyme systems which regulate molecular traffic across the endothelial cells. The development of the BBB is a complex process that leads to endothelial cells with unique permeability characteristics due to high electrical resistance and the expression of specific transporters and metabolic pathways.

Risau had a special interest in understanding the development, differentiation and maintenance of the BBB.

Risau and co-workers characterized a monoclonal antibody named $\mathrm{HT} 7$ that recognizes a highly glycosylated $48 \mathrm{kDa}$ protein, which belongs to the immunoglobulin-superfamily, which is expressed specifically on cerebral endothelium (Albrecht et al., 1990; Seulberger et al., 1990; 1991). The HT7 antigen is specifically expressed on chicken BBB endothelium but not on other endothelial cells (Risau et al., 1986; Albrecht et al., 1990). It is absent from the fenestrated choroid plexus endothelium but present on choroid plexus epithelium, the site of the cerebrospinal fluid barrier. Risau and co-workers investigated the expression of HT7 in the brain circumventricular organs which lack a BBB. Using immunohistochemical techniques they found that the protein was absent from the vascular system of pituitary, median eminence, subfornical organ, pineal gland, the organum vasculosum lamina terminalis and sinusoid blood vessels of the area postrema.

Embryonic mouse brain tissue transplanted on the chick embryo chorioallantoic membrane induced the expression of this protein in endothelial cells derived from the chick chorioallantoic vessels, which normally do not express this protein. Several homologues in different species have been described (Seulberger et al., 1992).

In collaboration with Hartwig Wolburg's laboratory, Risau performed a quantitative analysis of the structure and function of tight junctions in primary cultures of bovine brain endothelial cells using quantitative freeze fracture electron microscopy and ion and inulin permeability (Wolburg et al., 1994). By freeze fracture analysis, Risau demonstrated that $P$-face associated tight junctions particles rather than the number of branching frequency of tight junction strands correlates with BBB function. The complexity of tight junctions, defined as the number of branch points per unit length of tight junctional strands, decreased 5 hours after culture, but thereafter remained almost constant. In contrast, the association of tight junction particles with the cytoplasmic leaflet of the endothelial membrane bilayer ( $P$-face) decreased continuously with a major drop between 16 and 24 hours of culture. The $P$-face association of tight junctions could be restored to a certain extent by co-culture of endothelial cells with astrocytes or astrocyte conditioned medium. Co-culture with fibroblasts had no effect on P-face association. This study demonstrated that the cytoplasmic anchoring of the tight junctions plays an important 
role in the functioning of the BBB. Occludin is an integral membrane protein specifically associated with tight junctions. Although it has been demonstrated not to be necessary for the induction of functional junctions, it was found by establishing transfectants with an N-terminal truncated occuldin that the $\mathrm{N}$ terminal half of occludin plays an important role in tight junction assembly and maintenance of the barrier function.

Risau and co-workers (Klingler et al., 2000) demonstrated that following removal of calcium from the culture medium of epithelial cells in vitro, protein kinase $A$ is activated and subsequently is involved in the disruption of tight junctions.

Engelhardt and Risau (1995) proposed two phases of endothelial-neuroectodermal interactions leading to BBB differentiation. Their model is based on the observation that early during brain angiogenesis induction of specific genes can be observed in brain endothelial cells. In a subsequent phase, secondary interaction of "committed" brain endothelial cells in the developing neuroectodermal elements induce further endothelial differentiation, which leads to the fully functional BBB.

\section{Angiogenesis in glioma}

Glioblastoma is the most common and most malignant tumor of astrocytic origin in human adults. It includes about $50 \%$ of all glial tumors in humans. Glioblastoma multiforme is one of the most vascularized tumors, characterized by numerous and abnormal blood vessels, which rapidly proliferate and invade the brain tissue. Tumor blood vessels are characterized by several alterations consisting in an increase of the number of endothelial caveolae and fenestrations, prominent pinocytotic vesicles, lack of perivascular glial endfeet, as well as opening, loss and/or abnormal morphology of tight junctions, leading to an alteration of the vascular permeability and the loss of the BBB properties.

Risau and co-workers observed in low-grade glioma up-regulation of VEGF in some tumor cells, wheras in high-grade gliomas, in particular in glioblastoma, observed a significant up-regulation of VEGF mRNA in certain tumor areas (Plate et al., 1992; 1994). Histological analysis revealed a striking association of VEGF mRNA producer cells with areas of necrosis (Plate et al., 1992; 1994). Moreover, Risau and co-workers observed a tumor-stage up-regulation of VEGFR-1 and VEGFR-2 during tumor development and progression. VEGFR-2 transcripts were not detected in normal human adult brain vascular cells, whereas they were detected in vascular cells in high-grade gliomas, but not within low-grade gliomas (Plate et al., 1994).

The availability of a suitable rat glioma model has allowed Risau and co-worker to study the mechanisms of glioma angiogenesis in vivo (Plate et al., 1993). Rat C6 glioma cells, when transplanted into the brain of syngeneic recipient rats, form brain tumors which resemble human malignant glioma. In these experimental brain tumors, the expression of VEGF, VEGFR-1 and VEGFR-2 was strongly up-regulated during tumor development, as in malignant human glioma. Risau and co-workers have shown that VEGFR-2 is necessary for glioma angiogenesis. A dominantnegative mutant of VEGFR-2, whick lacked most of the intracellular domain, was able to inhibit wild-type VEGFR-2 activity in vitro (Millauer et al., 1994). In mice, tumor growth was significantly inhibited when cells producing a virus encoding the VEGFR-2 mutant were cotransplanted with tumor cells. Histological analy- sis revealed that tumor growth inhibtion was due to inhibition of angiogenesis (Millauer et al., 1994).

Since mutations in the tumor suppressor gene $p 53$ represent a common genetic alteration during glioma progression, Risau and co-workers analyzed whether $p 53$ may be a negative regulator of VEGF expression, i.e. whether a $p 53$ loss of function may up-regulate VEGF expression in vivo, since they observed a selective up-regulation of VEGF mRNA in certain glioma cells and hypothesized that these cells colud be deficient in p53 (Plate et al., 1992). However, subsequent studies failed to provide evidence that $p 53$ loss of function may up-regulate VEGF. In fact, the lack of co-expression of mutant p53 protein and VEGF in tissue sections of malignat glioma does not support this hypothesis (Plate et al., 1994).

\section{The role of platelet derived growth factor in angiogen- esis}

Platelelt derived growth factor (PDGF) is secreted by endothelial cells, presumably in response to VEGF, and facilitates recruitment of murals cells. Mutation of PDGF caused failure of recruitment of pericytes (Lindahl et al., 1997; 1998). A detailed analysis of the vessel development in both PDGF and PDGF-receptor mutant embryos showed that smooth muscle cells and pericytes initially form around vessel but, as vessel sprout and enlarge, PDGF signaling is required for co-migration and proliferation of supporting cells (Hellstrom et al., 1999).

Risau demonstrated that endothelial cells cultured on nitrocellulose membranes secreted a potent PDGF-like chemotactic factor almost exclusively onto the abluminal compartment (Zerwes and Risau, 1987).

Risau contributed to the protein sequencing, cDNA cloning and expression of functionally active platelet derived endothelial cell growth factor (PD-ECGF) and demonstrated that PD-ECGF has chemotactic activity for endothelial cells in vitro and angiogenic activity in vivo in the chick embryo chorioallantoic membrane assay (Ishikawa et al., 1989).

\section{Hypoxia and angiogenesis}

Oxygen tension is a crucial factor in new vessel growth, with regions of hypoxia which induce the expression of angiogenic molecules, such as VEGF-A, and hypoxia stimulates vasculogenesis (Hoper and Jhan, 1995). Hypoxia-inducible factor $-1 \alpha(\mathrm{HIF}-1 \alpha)$ is a transcription factor that is selectively stabilized and activated under hypoxic conditions, and that coordinates the adaptive response of tissue to hypoxia (Semenza, 1999). Hypoxia and the subsequent alteration of HIF-1 $\alpha$, can induce VEGF-A and stromal cell derived factor-1 (SDF-1), which stimulate migration of endothelial precursor during vasculogenesis (Ramirez-Bergeron et al., 2006).

One of the major drives to tumor angiogenesis is hypoxia, which is a characteristic of the tumor microenvironment and is a negative prognostic factor for cancer patient response to treatment and survival (Harris, 2002). Production of proangiogenic mediators by tumor cells and inflammatory leukocytes in response to hypoxia was demonstrated both in vitro and in vivo in hypoxic areas of tumors of different origin (Ryan et al., 2000). In particular, VEGF is one of the key angiogenic factors implicated 
in hypoxia-induced angiogenesis of a wide variety of tumors (Roftsad and Danielsen, 1999; Shweiki et al., 1992; Mizukami et al., 2004).

Risau and co-workers (Damert et al., 1997) asked whether the mechanism defined for hypoxia-induced VEGF expression in vitro are similarly involved and sufficient for up-regulation of VEGF gene expression in vivo. To this purpose, they used a lacZ reporter gene under the control of VEGF regulatory sequences in an experimental glioma model and demonstrated that deletion of the HIF-1 binding sites abolished reported gene expression in a special tumor cell subtype, the so-called perinecrotic palisanding (PNP) cells that flank necrotic regions within the tumors, indicating that transcriptional activation of VEGF expression in gliomas is mediated by HIF-1. Inclusion of 3' untranslated sequences from the VEGF gene in the reporter constructs resulted in an increased $\beta$-galactosidase expression in the PNP cells, suggesting that mRNA stabilization also contributes to VEGF up-regulation in glioblastoma cells. Moreover, combination of the 5' flanking region including the HIF-1 site along with 3' untranslated sequences produced increased level of $\beta$-galactosidase expression in PNP cells. Overall, these data provide experimental evidence that VEGF gene expression is activated in PNP cells by two distinct hypoxia-driven regulatory mechanisms.

Marti and Risau (1998) demonstrated that VEGF is induced in vivo by exposing mice to systemic hypoxia. VEGF induction was highest in brain, but also occurred in kidney, testis, lung, heart and liver. In situ hybridization analysis revealed that a distinct subset of cells within a given organ, such as glial and neurons in brain, tubular cells in kidney, and Sertoli cells in testis, responded to the hypoxic stimulus with an increase in VEGF expression. Furthermore, expression of VEGFR-1 was induced by hypoxia in endothelial cells of lung, heart, brain, kidney and liver.

Risau and co-workers (Marti et al., 2000) demonstrated that 48 and 72 hours after permanent middle cerebral artery occulsion in mouse, a strong increase in the number of newly formed blood vessel was recognizale at the border of infarction. Expression of VEGF and of VEGFRs was strongly up-regulated in the ischemic border and finally, HIF-1 and HIF-2 were increased in the ischemic border after 72 hours, suggesting a regulatory function for these factors.

\section{Acknowledgements}

Supported in part by MIUR (PRIN 2007), Rome, and Fondazione Cassa di Risparmio di Puglia, Bari, Italy.

\section{References}

ALBRECHT, U., SEULBERGER, H., SCHWARTZ, H., and RISAU, W. (1990). Correlation of blood-brain barrier function and $\mathrm{HT7}$ protein distribution in chick brain circumventricular organs. Brain Res 535: 49-61.

AUSPRUNK, D.H. (1986). Distribution of hyaluronic acid and sulfated glycosaminoglycans during blood vessel development in the chick chorioallantoic membrane. Am J Anat 177: 313-331.

BREIER, G., ALBRECHT, U., STERRER, S., and RISAU, W. (1992). Expression of vascular endothelial growth factor during embryonic angiogenesis and endothelial cell differentiation. Development 114: 521-532.

DAMERT, A., MACHEIN, M., BREIER, G., FUJITA, M.Q., HANAHAN, D., RISAU, W., and PLATE, K.H. (1997). Up-regulation of vascular endothelial growth factor expression in a rat glioma is conferred by two distinct hypoxia-driven mechanisms. Cancer Res 57: 3860-3864.

ENGELHARDT, B., and RISAU, W. (1995) The development of the blood-brain barrier. In The development of the blood-brain barrier. (Eds. Greenwood, J., Begley, D. and Segal, M.). London, Plenum Press, pp. 10-100.

FLAMME, I., VON REUTERN, M., DREXLER, H.C.A., SYDALI, S., and RISAU, W. (1995). Overexpression of vascular endothelial growth factor in the avian embryo induces hypervascularization and increased vascular permeability without alterations of embryonic pattern formation. Dev Bio/171: 399-414.

HARRIS, A.L. (2002). Hypoxia, a key regulatory factor in tumour growth. Nat Rev Cancer 2: 38-47.

HELLSTROM, M., KALEN, M., LINDAHL, P., ABRAMSON, A., and BETSHOLTZ, C. (1999). Role of PDGF-B and PDGFR-beta in recruitment of vascular smooth muscle cells and pericytes during embryonic blood vessel formation in the mouse. Development 126: 3047-3055.

HOPER, J., and JAHN, H. (1995). Influence of environmental oxygen concentration on growth and vascular density of the area vasculosa in chick embryos. Int $J$ Microcirc Clin Exp 15: 186-192.

ISHIKAWA, F., MIYAZONO, K., HELLMAN, U., DREXLER, H., WERNSTEDT, C., HAGIWARA, K., USUKI, K., TAKAKU, F., RISAU, W, and HELDIN, C.H. (1989). Identification of angiogenic activity and the cloning and expression of plateletderived endothelial cell growth factor. Nature 338: 557-562.

KABRUN, N., BÜHRING, H.J., CHOI, K., ULLRICH, A., RISAU, W., and KELLER, G. (1997). Flk-1 expression defines a population of early embryonic hematopoietic precursors. Development 124: 2039-2048.

KAPPEL, A., RÖNICKE, V., DAMERT, A., FLAMME, I., RISAU, W., and BREIER, G. (1999). Identification of vascular endothelial growth factor (VEGF) receptor2 (flk-1) promoter/enhancer sequence is sufficient for angioblast and endothelial cell-specific transcription in transgenic mice. Blood 93: 4284-4292.

KAPPEL, A., SCHLAEGER, T.M., FLAMME, I., ORKIN, S.H., RISAU, W., and BREIER, G. (2000). Role of SCL/Tal-1, GATA, and Ets transcription factor binding sites for the regulation of flk-1 expression during murine vascular development. Blood 96: 3078-3085.

KLINGLER, C., KNIESEL, U., BAMFORTH, S.D., WOLBURG, H., ENGELHARDT, B., and RISAU, W. (2000). Disruption of epithelial tight junctions is prevented by cyclic nucleotide-dependent protein kinase inhibitors. Histochem Cel/ Bio/113: 349-461.

KREMER, C., BREIER, G., RISAU, W., and PLATE, K.H (1997). Up-regulation of flk-1/vascular endothelial growth factor receptor 2 by its ligand in a cerebral slice culture system. Cancer Res 57: 3852-3859.

LINDAHL, P., JOHANSSON, B.R., LEEVEN, P., and BETSHOLTZ, C. (1997). Pericyte loss and microaneurysm formation in PDGF-B-dependent mice. SCience 277: 242-245.

LINDAHL, P., HELLSTROM, M., KALEN, M., KARLSSON, L., PEKNY, M., PEKNA, M., SORIANO, P., BETSHOLTZ, C. (1998). Paracrine PDGF-B/PDGF-Rbeta signaling controls mesangial cell development in kidney glomeruli. Development 125: 3313-3322.

MARTI, H.J., and RISAU, W. (1998). Systemic hypoxia changes the organ-specific distribution of vascular endothelial growth factor and its receptors. Proc Nat/ Acad Sci USA 95: 15809-15814.

MARTI, H.J., BERNAUDIN, M., BELLAIL, A., SCHOCH, H., EULER, M., PETIT, E., and RISAU, W. (2000). Hypoxia-induced vascular endothelial growth factor expression precedes neovascularization after cerebral ischemia. Am J Pathol 156: 965-976.

MATTHEWS, W., JORDAN, C.T., WIEGAND, G.W., PARDOLL, D., and LEMISCHKA, I.R. (1991). A receptor tyrosine kinase specific to hematopoietic stem and progenitor cell-enriched populations. Cel/65: 1143-1152.

MILLAUER, B., WIZIGMANN-VOSS, S., SCHNÜRCH, H., MARTINEZ, R., MØLLER, N.P.H., and RISAU, W. (1993). High affinity VEGF-binding and developmental expression suggest Flk-1 as a major regulator of vasculogenesis and angiogenesis. Cel/72: 835-846.

MILLAUER, B., SHAWER, L., PLATE, K.H., RISAU, W., and ULLRICH, A (1994). Glioblastoma growth inhibited in vivo by a dominant negative Flk-1 mutant. Nature 367: 576-579.

MIZUKAMI, Y., LI, J., ZHANG, X., ZIMMER, M.A., ILIOPOULOS, O., and CHUNG D.C. (2004). Hypoxia-inducible factor-1independent regulation of vascular endothelial growth factor by hypoxia in colon cancer. Cancer Res64:1765-1772.

PLATE, K.H., BREIER, G., WEICH, H.A., and RISAU, W. (1992). Vascular endothelial growth factor is a potential tumour angiogenesis factor in human gliomas 
in vivo. Nature 359: 845-848.

PLATE, H.K., BRIER, G., MILLAUER, B., ULLRICH, A., and RISAU, W. (1993). Upregulation of vascular endothelial growth factor and its cognate receptors in a rat glioma model of tumor angiogenesis. Cancer Res 53: 5822-5827.

PLATE, K.H., BREIER, G., WEICH, H.A., MENNEL, H.D., and RISAU, W (1994). Vascular endothelial growth factor and glioma angiogenesis: coordinate induction of VEGF receptors, distribution of VEGF protein and possible in vivo regulatory mechanisms. Int J Cancer 59: 520-529.

RAMIREZ-BERGERON, D.L., RUNGE, A., ADELMAN, D.M., GOHIL, M., and SIMON, M.C. (2006). HIF-dependent hematopoietic factors regulate the development of the embryonic vasculature. Dev Cel/11: 81-92.

RIBATTI, D. (2005). The crucial role of vascular permeability factor/vascular endothelial growth factor in angiogenesis: a historical review. $\mathrm{Br} J$ Haematol 128: 303-309.

RIBATTI, D. (2008). Napoleone Ferrara and the saga of vascular endothelial growth factor. Endothelium 15: 1-8.

RISAU, W. (1986). Developing brain produces an angiogenesis factor. Proc Nat/ Acad Sci USA 83: 3855-3859.

RISAU, W., HALLMANN, R., ALBRECHT, U., and HENKE-FAHLE, S. (1986). Brain induces the expression of an early cell surface marker for blood-brain barrierspecific endothelium. EMBO J5: 3179-3183.

RISAU, W., and LEMMON, V. (1988). Changes in the extracellular matrix during embryonic vasculogenesis and angiogenesis. Dev Bio/125: 441-450.

RISAU, W., GAUTSCHI-SOVA, P., and BOHLEN, P. (1988). Endothelial cell growth factors in embryonic and adult brain are related to human acidic fibroblast growth factor. $E M B O J 7$ : 959-962.

RYAN, H.E., POLONI, M., MCNULTY, W., ELSON, D., GASSMANN, M., ARBEIT, J.M., and JOHNSON, R.S. (2000). Hypoxia inducible factor-1 alpha is a positive factor in solid tumorgrowth. Cancer Res 60: 4010-4015.

ROFSTAD, E.K., and DANIELSEN, T. (1999). Hypoxia-induced metastasis of human melanoma cells:involvement of vascular endothelial growth factormediated angiogenesis. Brit J Cancer 80: 1697-1707.
RÖNICKE, V., RISAU, W., and BREIER, G. (1996). Characterization of the endothelium-specific murine vascular endothelial growth factor receptor-2 (flk1) promoter. Circ Res 79: 277-285.

SHALABY, F., ROSSANT, J., YAMAGUCHI, T.P., GERTSENSTEIN, M., WU, X.F. BREITMAN, M.L., and SCHUH, A.C. (1995). Failure of blood island formation and vasculogenesis in flk-1-deficient mice. Nature 376: 62-66.

SCHNÜRCH, H., and RISAU, W. (1991). Differentiating and mature neurons express the acidic fibroblast growth factor gene during chick neural development. Development 111: 1143-1154.

SCHNÜRCH, H., and RISAU, W. (1993). Expression of tie-2, a member of a nove family of receptor tyrosine kinases, in the endothelial cell lineage. Development 119: 957-968.

SEMENZA, G.L. (1999). Regulation of mammalian $\mathrm{O}_{2}$ homeostasis in hypoxiainducible factor-1. Ann Rev Cel/ Dev Biol 15: 551-578.

SEULBERGER, H., LOOSPEICH, F., and RISAU, W. (1990). The inducible bloodbrain barrier specific molecule HT7 is a novel immunoglobulin-like cell surface glycoprotein. EMBO J9: 2151-2158.

SEULBERGER, H., UNGER, C., ALBRECHT, U., and RISAU, W. (1991). The inducible blood-brain-barrier endothelium-specific antigen HT7, a novel immunoglobulin-like membrane glycoprotein. Ann N Y Acad Sci633: 611-614.

SEULBERGER, H., UNGER, C., and RISAU, W. (1992). HT7, neurothelin, basigin gp42 and OX-47 - many names for one developmentally regulated immunoglobulin-like surface glycoprotein on blood-brain barrier endothelium, epithelial tissue barriers and neurons. Neurosci Letters 140: 93-98.

SHWEIKI, D., ITIN, A., SOFFER, D., and KESHET, E. (1992). Vascular endothelial growth factor induced by hypoxia may mediate hypoxia initiated angiogenesis. Nature 359: 843-845.

ZERWES, H.G., and RISAU, W. (1987). Polarized secretion of a PDGF-like chemotactic factor by endothelial cells in vitro. J Cel/ Bio/105: 2037-2041.

WOLBURG, H., NEUHAUS, J., KNIESEL, U., KRAUSS, B., SCHNIDT, E.M., ÖCAKAN, M., FARRELL, C., and RISAU, W. (1994). Modulation of tight junction structure in blood-brain barrier endothelial cells. J Cel/ Sci107: 1347-1357.

\section{Further Related Reading, published previously in the Int. J. Dev. Biol.}

See Special Issue Pattern Formation edited by Michael K. Richardson and Cheng-Ming Chuong at: http://www.ijdb.ehu.es/web/contents.php?vol=53\&issue=5-6

\section{Embryonic development of the proepicardium and coronary vessels}

Anna Ratajska, Elzbieta Czarnowska and Bogdan Ciszek

Int. J. Dev. Biol. (2008) 52: 229-236

Coexpression of Notch 3 and Rgs 5 in the pericyte-vascular smooth muscle cell axis in response to pulp injury

Henrik Lovschall, Thimios A. Mitsiadis, Knud Poulsen, Kristina H. Jensen and Annette L. Kjeldsen

Int. J. Dev. Biol. (2007) 51: 715-721

Vasculogenesis and angiogenesis in the mouse embryo studied using quail/mouse chimeras

Michel Pudliszewski and Luc Pardanaud

Int. J. Dev. Biol. (2005) 49: 355-361

Parallels in invasion and angiogenesis provide pivotal points for therapeutic intervention

Suzanne A. Eccles

Int. J. Dev. Biol. (2004) 48: 583-598

Multilineage hematopoietic progenitor activity generated autonomously in the mouse yolk sac: analysis using angiogenesis-defective embryos Christine Rampon and Philippe Huber

Int. J. Dev. Biol. (2003) 47: 273-280

5 yr ISI Impact Factor $(2008)=3.271$

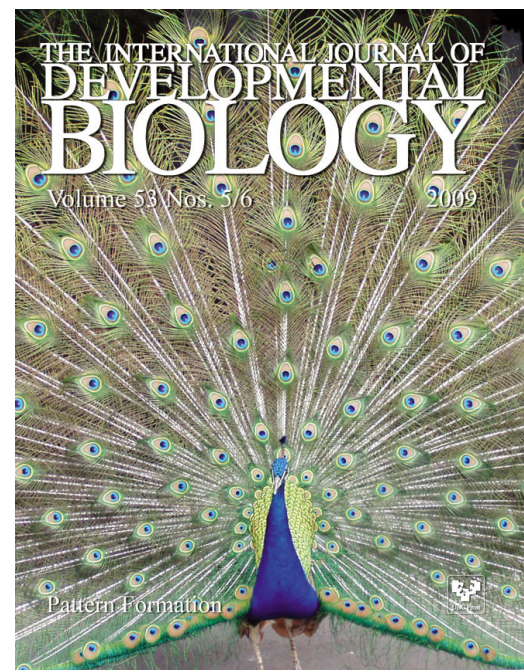

